\title{
CORRESPONDENCE
}

\section{ON PYROXENE MOLECULES IN THE CIPW NORM}

SIR,-Chayes (1963) has constructed two sets of strange rules of calculating the norm of igneous rocks. Contrary to all evidence he charges that these rules are implied in an old paper of mine published thirty-two years ago under the title : "Proposed changes in the Calculation of Norms of Rocks". However, the changes advocated were in the presentation of the norms. They imply small and obvious modifications in the calculations, hence the title. But they imply no changes in the principles of the rules of calculation ; this, I believe, is amply demonstrated by the text. However inveigled by the title Chayes (1963) imputes to me certain ideas that are not only alien but straight out contrary to my convictions.

The very object of my paper was to bring clearness and conciseness into the norm symbols. This may be explained by referring to the annexed table:-

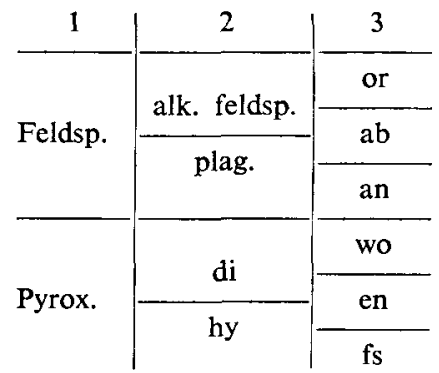

The two most important normative mineral groups, quantitatively, are feldspar and pyroxene. One way of recording them is shown in column 1. But this way is not very concise, for nothing is said about the nature of either feldspar or pyroxene. Column 2 is better, but not satisfactory. Full information can only be extracted from column 3 , which is the only column displaying the complete chemical composition of the minerals. In the same way the symbol $o l$ (representing olivine) is less precise than the symbols $f o$ and $f a$ (representing the constituent silicates). In my opinion the CIPW norm does become clearer and more concise if stated in terms of the symbols listed in column 3 , together with the symbols $f o$ and $f a$.

These were the only changes proposed by me, in 1931, neither more nor less. There are no hidden implications in these changes, there are no strings attached. The changes were almost immediately accepted by a great number of petrologists, including my friend and teacher Dr. H. S. Washington, the founder of the CIPW norm.

There was one objector: Tilley (1933) wrote about the doctoring of the norm, taking strong exception to my proposals on the ground that wo and en are incompatible in natural rocks. Apparently Tilley did not read my paper carefully: excerpt, (Barth p. 4): “... the natural conditions would be matched more closely by assuming a mix-crystal between $\mathrm{CaSiO}_{3}, \mathrm{MgSiO}_{3}$, and $\mathrm{FeSiO}_{3}$, and for this reason the norm should be calculated in terms of these silicates separately, with the understanding that these silicates combine to form a mix-crystal much in the same way as or, $a b$, and $a n$, combine to form feldspar...".

If Tilley's argument is accepted, it should be used for the feldspar symbols as well; consequently the use of $o r, a b$, and $a n$ should be discontinued, as $a b$ and $a n$ are modally incompatible !

Chayes $(1963$, p. 8$)$ writes: "In rocks over-saturated with silica the only distinction between Barth norms (vintage 1931) and CIPW norms is precisely that singled out by Tilley." Chayes continues: "In under-saturated rocks, however, the situation is considerably more complicated ... what he (Barth) 
suggests in (his paper) is no more than a change in the method of stating the norm. In fact, he (Barth) does not tell how to calculate the new norm at all ...".

This is an honest and correct comment on my old paper. Here are Chayes' own words that I did nothing more than change the methods of stating the norm. I did not propose to change the principles of the rules of calculating the norm, and I was never concerned with teaching anybody how to calculate a " new" norm. This, I am sure, was understood by all petrographers in 1931, and is apparently also clear to Chayes. Nevertheless Chayes writes (p. 9): "Curiously, in both editions of his own text Barth (1951 and 1962) lists ... the correct CIPW rules for calculation." Indeed, Chayes must be a determined doubter, for he suggests a peculiarly forced interpretation of the fact that Ono (1962) correctly follows my rules of 1931 in his large publication of machine-computed norms.

For some reason that I cannot explain, Chayes seems convinced that I want to desilicate the di molecule.

Excerpt Chayes, p. 8: "Why did CIPW prefer the clumsy and apparently arbitrary device of forming $d i, o l$, and $n e$, desilicating the $d i$ only if silica were insufficient to form $l c$, and silicating ol only if silica remained after all alkalis had been converted to feldspar?" My answer is that I do not find this device clumsy. Chayes later admits that it "is about the simplest way to do the business ". The device is certainly not arbitrary, for modally it is a petrographical necessity. I have never questioned the justification of it, nor have I heard any one else do so. But in spite of all this, Chayes fabricates two sets of so-called "Barth-type norms", and insists that I want to dispense with the CIPW conventions.

At this point it is justified to question the manner in which Chayes goes after the truth. If he became confused by drinking my vintage 1931, he should have consulted some younger vintages - or he should have sent me a letter and asked. Scores of calculations of true Barth-type norms have been published in the last thirty-two years, and by using some very simple arithmetic it is easy to see how the pyroxene molecules are desilicated.

Finally, Chayes intimates (p. 10) that I do not care for agreement between norms and modes of jgneous rocks: ..." And if this is not the major objective of a norm, why should normative parameters be named after minerals ?".

I shall answer by quoting myself (Barth, Abstract, p. 1): "... these changes will improve the norm by bringing all the ferro-magnesian minerals into a closer approach to natural conditions, by making it easier to survey their composition and rendering calculations simpler."

Mineralogisk-Geologisk Museum,

TOM. F. W. Barth.

SARSGT. 1, OsLo.

1st April, 1963.

\section{REFERENCES}

Barth, T. F. W., 1931. Proposed change in calculation of norms of rocks. Miner. Petr. Mitt., 42, 1-7.

1951, 1962. Theoretical Petrology. John Wiley and Sons, Inc., New York. 1st and 2nd editions.

Chayes, F., 1963. On pyroxene molecules in the CIPW norm. Geol. Mag., $100,7-10$.

ONo, K., 1962. Chemical Composition of Volcanic Rocks in Japan. Geol. Survey of Japan.

TILley, C. E., 1933. On the proposed doctoring of the norm. Miner. Petr. Mitt., 43, 67-8.

SIR,--The burden of Dr. Barth's 1931 note is that conventions governing the computation of normative $d i, h y$, and $o l$ are mineralogically unrealistic. It did not occur to me at the time of writing, and seems incredible to me now, that an essay largely devoted to a detailed and rather persuasive criticism of a set of computational conventions would conclude with the tacit suggestion 
that these unsatisfactory conventions be continued in force and the explicit recommendation that the method of reporting the results be so modified as to eliminate evidence bearing on this matter. So I must plead guilty to supposing that Dr. Barth intended his title to mean what it said. I regret that this failure of imagination has caused him such annoyance, but can see no other reason to modify my position.

We are evidently in agreement that some general rule governing the formation of, and allocation of silica to, $p x$ and $o l$ molecules is indispensable in the treatment of under-saturated rocks, and also that the CIPW conventions provide a remarkably ingenious solution to the second but a not entirely satisfactory solution to the first of these problems. We are probably also in agreement that there is no fundamental objection to trying other appropriate solutions.

Trying alternative solutions by hand calculation is a tedious, time-consuming business. If the matter were of sufficient importance, however, it would be a relatively simple matter to prepare a machine program which would computein a single pass- norms based on as many sets of alternative $p x$-ol conventions as seemed useful, for as many analyses as were available. All we need are the sets of alternative conventions, and my note was prompted largely by a desire to stimulate presentation and discussion of these. The conventions that $\mathrm{Mg} / \mathrm{Fe}$ is the same in $o l, h y$, and $d i$, that $\mathrm{Ca}:(\mathrm{Fe}+\mathrm{Mg})=1: 1$ in $d i$, that $d i$ be desilicated only if available $\mathrm{SiO}_{2}$ is insufficient to form $l c$, and that $o l$ be silicated only after aluminates have been converted to $a b$, or, and an were proposed by CIPW in 1902. Are they still the best we can do?

GEOPHYSICAL LABORATORY,

F. Chayes.

2801, UPTON STREET,

WASHINGTON 8, D.C., U.S.A.

8th April, 1963.

\section{VOLCANIC ROCKS OF THE ORAMUTIA SECTION, CENTRAL KENYA}

SIR,-Dr. Rast (Geol. Mag., 100, 94-95) attributes an assumption to me which I have nowhere expressed. I have stated my opinion quite clearly in a letter to Nature $(196,365-7,1962)$, accepting that there is considerable evidence in favour of the lithostatic-load compaction and welding concept which he favours. I do not consider that the recognition of famme formed from vesiculation areas in the Kenya froth flows " must inevitably" influence the ignimbrite hypothesis. It is however a perfectly reasonable inference to draw that it may: another geologist, Grange, of the same calibre as Marshall, working on the same rocks, considered the "ignimbrites" to be lavas, and the structure to be closely related to fluidal banding in lavas. Since this is exactly what $I$ have recognized in the Kenya froth-flows, and the fiamme structure is almost identical in appearance, I do not feel that this is an unreasonable inference: but I am chiefly concerned with the Kenya field, and my primary object was to state an alternative interpretation for rocks which have been called ignimbrites by other geologists : I leave any further development of my tentative suggestion to others far more qualified than myself.

"Fiamme" is used by me and by Rast in a non-genetic sense: this has the backing of several authorities including Zavaritsky ( $\mathrm{Akad}$. Nauk. SSSR, Izv., Ser. Geol. 3, II). I have made clear, I believe, in the above paragraph, that I am not concerned with the implications of fiamme as a structure capable of only one mode of genesis: I am concerned with possible implications of the Kenya type of fiamme.

After eleven years of intermittent engagement with this problem I am of course fairly well acquainted with the vast store of literature which it has engendered. I must confess that I find it to be a jungle of terms, which are used by various authors in various ways. I find the distinction between welded tuffs and ignimbrites vaguely defined: academically speaking, that is in terms of the original writer's meaning, there is a distinction, but since some of the 